\section{Revista}

Ibero-Americana

de Estratégıa

\title{
PROPOSTA DE UMA ESTRATÉGIA PARA O DESENVOLVIMENTO DE NOVOS CURSOS DE ENSINO SUPERIOR
}

PROPOSAL FOR A STRATEGY FOR DEVELOPMENT OF NEW COURSES OF HIGHER EDUCATION

PROPUESTA DE UNA ESTRATEGIA PARA EL DESARROLLO DE NUEVOS CURSOS DE EDUCACIÓN SUPERIOR

\section{Emerson Wagner Mainardes}

Doutor em Administração pela Universidade da Beira Interior - UBI - Covilhã, Portugal E-mail: emerson.wm@sapo.pt (Brasil)

\section{Maria José Silva}

Doutora em Gestão pela Universidade da Beira Interior - UBI - Covilhã, Portugal Professora Auxiliar da Universidade da Beira Interior - UBI - Covilhã, Portugal E-mail: msilva@ubi.pt (Portugal)

\section{Maria José Domingues}

Doutora em Engenharia de Produção pela Universidade Federal de Santa Catarina - UFSC Professora da Fundação Universidade Regional de Blumenau - FURB

E-mail: mariadomingues@furb.br (Brasil) 


\title{
PROPOSTA DE UMA ESTRATÉGIA PARA O DESENVOLVIMENTO DE NOVOS CURSOS DE ENSINO SUPERIOR
}

\section{RESUMO}

Neste estudo, apresenta-se uma proposta de um modelo que sistematiza o processo de construção de um novo curso de ensino superior. A partir dos fundamentos que norteiam as estratégias em serviços e da oferta de novos serviços, e apoiado nos estudos encontrados sobre o desenvolvimento de novos serviços para o setor educacional, foi possível a construção do modelo, que é dividido em: antecedentes, desenvolvimento e implementação do novo curso no ensino superior. Ao final da pesquisa, apresenta-se um estudo de caso de uma instituição de ensino superior que segue determinados procedimentos para oferecer um novo curso superior e que permitiu comparar o modelo proposto com os processos realizados pela instituição investigada. $\mathrm{O}$ modelo proposto orienta a oferta de novos cursos ao mercado, bem como dá um primeiro passo para a investigação científica sobre a temática.

Palavras-chave: Estratégia em Serviços; Serviços Educacionais; Novos Cursos de Ensino Superior; Gestão Universitária.

\section{PROPOSAL FOR A STRATEGY FOR DEVELOPMENT OF NEW COURSES OF HIGHER EDUCATION}

\begin{abstract}
This study has proposed a model that systematizes the process of the construction of a new course of higher education. The fundamentals that guide the strategies in services and the new services development, and supported in studies found on the new services development for the education sector, allowed for the construction of the model, which is divided into: antecedents, development, and implementation of the new course in higher education. A case study at a higher education institution that follows certain procedures to offer a new course allowed us to compare the proposed model with the processes undertaken by the institution investigated. The proposed model guides the provision of new courses to the market and gives a first step in scientific research on the topic.
\end{abstract}

Keywords: Strategies in Services; Educational Services; New Courses in Higher Education; University Management. 


\section{PROPUESTA DE UNA ESTRATEGIA PARA EL DESARROLLO DE NUEVOS CURSOS DE EDUCACIÓN SUPERIOR}

\section{RESUMEN}

El estudio ha propuesto un modelo que sistematice el proceso de construcción de un nuevo curso de educación superior. A partir de los fundamentos que orientan las estrategias en los servicios y de la oferta de nuevos servicios, y apoyado en los estudios encontrados sobre el desarrollo de nuevos servicios para el sector educacional, fue posible la construcción del modelo, que se divide en: antecedentes, desarrollo e implementación del nuevo curso en la enseñanza superior. Al final de la investigación, se presenta un estudio de caso de una institución de educación superior que sigue determinados procedimientos para ofrecer un nuevo curso superior que permitió comparar el modelo propuesto con los procesos realizados por la institución investigada. El modelo propuesto orienta la oferta de nuevos cursos al mercado y da un primer paso para la investigación científica sobre la temática.

Palabras-clave: Estrategia en Servicios; Servicios Educacionales; Nuevos Cursos de Educación Superior; Gestión Universitaria. 
Proposta de uma Estratégia para o Desenvolvimento de Novos Cursos de Ensino Superior

\section{INTRODUÇÃO}

A literatura sobre serviços vem crescendo intensamente desde os anos 1960 (Miles, 2001). Isso se deve ao fato que o setor de serviços vem apresentando crescimento acima da média (SegalHorn, 2006). Nesse contexto, setores como tecnologia da informação, finanças, transportes e comunicações ganham importância no produto interno bruto das nações, tanto em países desenvolvidos quanto em países em desenvolvimento.

Entre os serviços em crescimento estão os educacionais. Nunca se buscou tanta educação como no início do século XXI (Michael, 2004). O conhecimento tornou-se ferramenta necessária para o sucesso tanto pessoal quanto profissional dos indivíduos, sendo que esse conhecimento temse obtido nos bancos escolares (Palácio, Meneses \& Pérez, 2002).

Em países desenvolvidos, a competição por alunos acirra-se por causa de um mercado que diminui, afinal as taxas de natalidade desses países decrescem a cada ano (Tam, 2007). Já em países em desenvolvimento, o ensino superior cresce como resultado do aumento de demanda, da necessidade de profissionais qualificados, das pressões governamentais, da busca por maior qualidade de ensino, do crescimento do acesso ao ensino superior e da necessidade de prestar contas à sociedade pelo uso de recursos públicos e privados escassos (Meyer Jr e Murphy, 2003). Ou seja, constata-se que na maior parte dos países do globo começa-se a observar uma oferta que supera a demanda por educação em nível superior. Com uma concorrência crescente, as instituições de ensino superior (IESs) buscam caminhos para sobreviverem. Um desses caminhos é o desenvolvimento de novos serviços (Mok, 2003).

Novos serviços de ensino superior apresentam diversos sentidos. Para Findlow (2008), pode revelar-se de diversas formas: (1) o desenvolvimento de pesquisas dentro das universidades; (2) métodos de ensino inovadores; (3) o uso de novas tecnologias de informação e comunicação (TICs) para o ensino; (4) a oferta de novos cursos de ensino superior que atendam as necessidades específicas de conhecimentos da atualidade. Entre essas formas que promovem a ampliação do serviço educacional, realça-se a criação de novos cursos de ensino superior, como o tema do estudo aqui descrito, dado que, genericamente, é um fenômeno ainda pouco estudado e revela-se pertinente que se busque um conhecimento mais aprofundado, tanto em termos acadêmicos, quanto em termos práticos.

Criar um novo curso de ensino superior não difere-se da criação de qualquer outro novo serviço. Para Wolff (2008), o desenvolvimento de novos serviços educacionais equivale a criação de um novo produto, porém com as peculiaridades que caracterizam os serviços (intangibilidade, heterogeneidade, simultaneidade de produção e consumo, perecibilidade). 
Em contrapartida, Hynes e Richardson (2007) demonstram em seu estudo que as IESs carecem de estratégias e processos adequados quando decidem desenvolver um novo curso superior. A falta de critérios e de um processo formalizado no tanto desenvolvimento quanto na oferta de um novo curso de ensino superior tem levado uma série de novos cursos ao fracasso. Essa falta de planejamento, resulta em poucos alunos para preencherem as primeiras turmas e no fechamento de alguns bons cursos por não corresponderem às expectativas de procura de alunos.

Considerando essa realidade, a questão que se busca responder é: como desenvolver um novo curso de ensino superior com maiores probabilidades de sucesso?

Para responder a essa pergunta, o objetivo dessa investigação visa propor um modelo que auxilie os gestores universitários no desenvolvimento e na implementação de um novo curso de ensino superior. Como objetivos específicos buscou-se: (i) identificar os fatores que levam ao desenvolvimento de um novo curso de ensino superior; (ii) determinar os passos a serem seguidos na construção de um novo curso de ensino superior; (iii) definir as etapas que fazem parte do processo de implementação de um curso de ensino superior recém- desenvolvido.

Pretendeu-se, dessa forma, apresentar um modelo que auxilie a tomada de decisão dos gestores das IESs quanto ao desenvolvimento e implementação de novos cursos de ensino superior. Para tanto, inicialmente fez-se uma revisão teórica das estratégias das empresas de serviços, no desenvolvimento de novos serviços, em geral, e educacionais, em particular. Em seguida, apresentou-se a proposta de um modelo e um caso para comparar o modelo proposto com a realidade de uma IES. Finaliza-se com a discussão do modelo proposto, suas contribuições e limitações.

\section{ESTRATÉGIA EM SERVIÇOS}

As organizações de serviços que pretendem sobreviver e expandir-se no mercado onde atuam devem planejar os serviços oferecidos, de modo consistente, preciso e flexível, focalizando suas atenções nos fatores e nas orientações que levam um cliente, ou usuário, a optar pela organização (Blois, 1983). Isso significa que tais organizações precisam adotar estratégias que lhes permitam competir com maior probabilidade de sucesso no ambiente onde se inserem, ou seja, sua sobrevivência e expansão vinculam-se à escolha de um direcionamento: as estratégias competitivas (Rebelo e Erdmann, 2003). De um modo geral, as definições de estratégia sempre focalizam o reforço da posição competitiva da empresa no mercado por meio da ampliação de recursos e capacidades ou da escolha de um posicionamento adequado (Aranda, 2003).

Revista Ibero-Americana de Estratégia - RIAE, São Paulo, v. 10, n. 2, p. 58-83, mai./ago. 2011. 
Proposta de uma Estratégia para o Desenvolvimento de Novos Cursos de Ensino Superior

As estratégias competitivas originam-se na literatura de estratégia por meio das obras de Porter (1980, 1985). Foram desenvolvidas para a indústria, porém podem ser adaptadas ao contexto das empresas que produzem serviços. Segundo Porter (1985), são três os níveis da estratégia: a corporativa, considerado o nível mais alto, que orienta e conduz a organização no meio onde ela está inserida; a de negócios (ou competitiva), um nível intermediário na hierarquia das estratégias empresariais, que visa a obtenção de vantagens competitivas para cada unidade de negócios, sendo que os objetivos de tal unidade (missão e visão) devem seguir o que foi estabelecido na estratégia corporativa; a funcional, a base, onde ocorre a tradução e organização operacional das capacidades e recursos com o o objetivo de dar apoio e consistência às decisões tomadas nos níveis mais altos das decisões estratégicas. Esses três níveis de estratégias competitivas são como uma fórmula que define o modo da empresa competir no mercado e que combina fins (metas) e meios (políticas).

Especificamente com relação às empresas de serviços, as estratégias competitivas, para Fitzsimmons e Fitzsimmons (2000), dificilmente são generalizáveis, em razão da diversidade de empresas que participam desse setor. As empresas de serviços têm de superar várias dificuldades competitivas, tais como barreiras à entrada relativamente baixas, poucas oportunidades para as economias de escala e limitações para acessar outros mercados distantes de sua área de atuação (Mathyssens e Vandenbempt, 1998). Além disso, os serviços apresentam diferenças marcantes, como a natureza predominantemente intangível do serviço ou o envolvimento do cliente no processo de produção (embora não seja sempre aplicável a todos os serviços), que criam a necessidade de uma abordagem de estratégia específica para as empresas de serviços (Lovelock, 1996).

A estratégia nas empresas de serviços tem como objetivo fazê-las reagir às mudanças ambientais que afetam a empresa perante a concorrência (Macintosh, 2009). As decisões estruturais, de processos e de infraestruturas que configuram as estratégias em serviços influenciam diretamente o nível de flexibilidade do sistema de entrega do serviço aos clientes (Bucki e Pesqueux, 2000). Quando os níveis de flexibilidade em todas as dimensões do sistema de prestação de serviços relacionadas à estratégia escolhida e implementada estão adequados, isso afeta diretamente seu desempenho operacional (Carman e Langeard, 1980). Porém, observa-se grande dificuldade em medir o ambiente do serviço, uma vez que fatores como qualidade ou satisfação são abstratos e de difícil mensuração, porém são cruciais para o sucesso da empresa (Aranda, 2003).

Para Bateson e Hoffman (2001), uma empresa de serviços, para alcançar o sucesso, deveria funcionar baseando-se em algumas estratégias operacionais bastante focalizadas: um segmento-alvo bem definido, um conceito de benefícios dos serviços oferecidos claramente determinado, um sistema de gerenciamento de processos e operações bem planejado, uma preocupação constante na

Revista Ibero-Americana de Estratégia - RIAE, São Paulo, v. 10, n. 2, p. 58-83, mai./ago. 2011. 
oferta de novos serviços e uma imagem positiva dos serviços que oferece. Por outro lado, às organizações de serviços é exigida a adoção de estratégias múltiplas (por causa de ameaças competitivas ou por necessidade de crescimento), e, muitas vezes, se deparam com uma complexidade gerencial que tende a levá-las à perda de foco e de controle.

Portanto, há a necessidade de se estabelecer dimensões estratégicas de uma estrutura de serviços, objetivando contornar a dificuldade em se desenvolver estratégias gerais para o setor dos serviços (Nayyar, 1990; Blok et al, 2010). Nesse sentido, as estratégias de serviços devem considerar as peculiaridades próprias do serviço (intangibilidade, perecibilidade, heterogeneidade, simultaneidade), a necessidade de um relacionamento mais próximo com os clientes, a personalização que caracteriza cada serviço, a natureza da demanda e fornecimento, e as formas de atendimento em serviços (Fitzsimmons e Fitzsimmons, 2000). Esses fatores, delimitam o desenvolvimento de estratégias em empresas de serviços. Complementarmente, Jonhston (1999) e Tannery (2001) estabeleceram que as principais estratégias para os serviços se relacionam: à escolha do mercado-alvo, ao desenvolvimento de novos serviços, ao relacionamento entre o cliente (ou usuário) e o prestador do serviço, aos fluxos e processos necessários para executar o serviço, à qualidade e aos resultados dos serviços prestados (satisfação, lealdade), à estruturação do sistema de entrega. Em resumo, a formulação da estratégia competitiva em serviços é projetada para combinar as capacidades operacionais do sistema de prestação de serviços com as necessidades dos consumidores. Dessa forma, a estratégia do setor de serviços tende a ser baseada em aspectos associados à diferenciação da oferta de serviços (Armistead 1990).

Segundo Fitzsimmons e Fitzsimmons (2000), são quatro os elementos que formam a visão estratégica do setor de serviços: (a) o sistema de prestação do serviço; (b) a estratégia operacional; (c) o conceito do serviço; e (d) o segmento do mercado-alvo. Na análise desses quatro elementos, percebe-se a importância de se determinar os processos na criação e manutenção dos serviços oferecidos pela empresa. Isto é, ao desenvolver um novo serviço, a empresa deve planejar o processo de modo estruturado, algo que vem a aumentar as probabilidades de sucesso da nova oferta.

Em razão da menor necessidade de grandes investimentos em instalações, à velocidade de imitação, e à ameaça de novos concorrentes têm sido sugerido às empresas prestadoras de serviços, como uma estratégia eficaz que acelerem seus processos e realizam o desenvolvimento de novos serviços continuamente (Skaggs e Youndt, 2004). No entanto, parece existir uma inércia considerável nas organizações de serviços, que dificultam as mudanças necessárias nas estruturas e estratégias para facilitar o desenvolvimento de novos serviços. Faltam processos estruturados para tais ações (Edvardsson, Haglund e Mattsson, 1995, Hurmelinna-Laukkanen e Ritala, 2010). As 
Proposta de uma Estratégia para o Desenvolvimento de Novos Cursos de Ensino Superior

empresas de serviço que são bem- sucedidas em desenvolver novos serviços ao longo do tempo tendem a ter uma estratégia clara para os seus novos serviços (Storey e Kelly, 2001).

\subsection{DESENVOLVIMENTO DE NOVOS SERVIÇOS}

Como comentado, entre as formas de superar a concorrência, as empresas de serviços podem adotar como estratégia, o desenvolvimento de novos serviços, afinal um produto ou serviço deve satisfazer as necessidades ou desejos dos seus clientes no momento em que é oferecido ao mercado (Kindström e Kowalkowski, 2009). Para tanto, são necessários recursos tangíveis e intangíveis no processo de desenvolvimento desses serviços, com o objetivo de conhecer a preferência e a percepção dos consumidores potenciais, com vistas a minimizar o risco de insucesso no lançamento desses serviços (Santos 2003, Voss e Hsuan, 2009). Nesse sentido, essas organizações devem desenvolver métodos efetivos para a criação de novos serviços, otimizando o uso de seus recursos e chegando na frente da concorrência (Froehle e Roth 2007). Conforme apontaram Syson e Perks (2004), o foco em novos serviços exige planejamento de todas as fases (design, análise, desenvolvimento, implementação e avaliação), com a integração de todos os recursos da organização (intelectuais, organizacionais, físicos). Serviços novos, geralmente, requerem mais apoio da estrutura organizacional da empresa, bem como desenvolvimento de recursos humanos, definição de processos, e apoio da administração (Droege, Hildebrand e Forcada, 2009).

Jong e Vermeulen (2003) fizeram uma ampla revisão dos estudos em desenvolvimento de novos serviços. Essa revisão, que cobriu o período de 1988-2002, comprovou a pouca presença de pesquisas a respeito do desenvolvimento de novos serviços, ao encontrar somente 52 artigos científicos e 7 livros/capítulos de livros que tratam do desenvolvimento de novos serviços, principalmente serviços financeiros (66\% das pesquisas efetuadas). Dessa revisão saiu o modelo proposto pelos autores. Segundo eles, o desenvolvimento de novos serviços, de forma genérica, é o gerenciamento de atividades-chave: quanto às pessoas, envolvimento das equipes de contato direto com clientes e suporte gerencial; em termos de estrutura, disponibilização de ferramental adequado, desenvolvimento de equipes multifuncionais, avaliação dos recursos necessários e disponíveis, viabilização de testes de pré-lançamento, pesquisas de mercado. A adequação da organização para o desenvolvimento de novos serviços é o que possibilita que tais serviços tornem-se um sucesso no mercado.

Outros estudos também contribuem para a construção de um modelo ideal de desenvolvimento de novos serviços de forma genérica:

Revista Ibero-Americana de Estratégia - RIAE, São Paulo, v. 10, n. 2, p. 58-83, mai./ago. 2011. 
- Urban e Hauser (1993) apresentaram um modelo de processos para o desenvolvimento de novos serviços, que se baseou em estratégias pró-ativas, que contemplam cinco fases (identificação de oportunidades, design do serviço, testes, introdução e gerenciamento do ciclo de vida do serviço). Entre cada fase do processo, os gestores decidem se o processo continua ou se deve ser abandonado;

- No estudo de Mendes e Toledo (1997), o desenvolvimento de um novo serviço deve seguir uma sequência de atividades - desenvolver uma estratégia comercial corporativa e uma estratégia para o novo serviço; geração formal de ideias; seleção de ideias; desenvolvimento do conceito (serviço núcleo e serviços periféricos) e do processo de produção do serviço; análise de viabilidade; implementação; teste de mercado (projeto piloto); comercialização;

- Para Syson e Perks (2004), uma equipe de trabalho integrada e multifuncional, conjugada com a adoção de processos formais de organização e gestão, e de métodos de avaliação em cada etapa do processo, corresponde ao que se considera como as melhores práticas de gestão no processo de desenvolvimento de novos serviços;

- No modelo proposto por Garcia e Roblin (2008), o desenvolvimento de novos serviços é um ciclo circular: inicia-se com questões iniciais (oportunidade de mercado, recursos necessários, posicionamento da concorrência, entre outros), segue para uma proposta de plano de ação para o novo serviço, com posterior implementação, observação e reflexão, gerando revisões e mudanças no novo serviço; implementam-se as mudanças, analisa-se novamente e faz-se novas propostas de mudanças; avalia-se novamente e propõem-se novas mudanças e assim sucessivamente. Em suma, um serviço é dinâmico e exige ajustes frequentes;

- No modelo de Ross (2008), para a criação de um novo serviço, a coleta de informações é fundamental, tanto no âmbito externo da organização (assuntos socioculturais, político-legais, internacionais, tecnológicos e econômicos, além de clientes, fornecedores, serviços substitutos, barreiras de entrada de novos provedores do mesmo serviço, competitividade do mercado) quanto no meio interno da empresa (recursos físicos, humanos e financeiros que o desenvolvimento do novo serviço exigirá). Com essas informações em mãos, os decisores da organização iniciam um processo formal de desenvolvimento do serviço;

É importante destacar que todos os autores citaram que um procedimento formalizado de desenvolvimento de novos serviços é vital para aumentar as chances de sucesso do serviço 
Proposta de uma Estratégia para o Desenvolvimento de Novos Cursos de Ensino Superior

inovador. Esse deve ser o ponto de partida para as IESs no desenvolvimento de novos serviços educacionais.

\subsection{DESENVOLVIMENTO DE NOVOS SERVIÇOS EDUCACIONAIS}

Se existe pouca literatura em termos de desenvolvimento de novos serviços, quando se trata do mercado de ensino superior, as pesquisas são raras. Na revisão apresentada por Jong e Vermeulen (2003), por um lado, observou-se que não há nenhum estudo a respeito desse mercado.

Por outro lado, o mercado de ensino superior torna-se cada vez mais competitivo e, em razão disso, as organizações do setor necessitam de ferramentas de gestão adequadas para poderem sobreviver nesse mercado bastante complexo.

Todo esse processo torna-se complexo porque as organizações que oferecem ensino não podem ser consideradas empresas comuns (Michael 2004). Algumas das características da organização das IESs são: sua atividade principal baseia-se em conhecimento; a base da organização assenta-se na divisão em disciplinas e na especialização do conhecimento, criando uma estrutura fragmentada em departamentos; seu processo de tomada de decisão é difuso e descentralizado; as IESs têm capacidade de inovação e de adaptação em cada área científica, mas, em um nível estrutural, se mostram muito resistentes à mudança (Cardoso 2005).

Em contrapartida, é preciso perceber que as instituições educacionais de nível superior na sociedade atual tornaram-se organizações que provêem serviço educacional. Para prover educação a um nível desejado, e resistir a competição nesse mercado, as IESs têm de construir uma instituição que respeite os princípios atuais de organizações prestadoras de serviço, com uma administração semelhante a outras empresas do setor de serviços. Isso significa introduzir a noção "negócio" para instituições educacionais e atender as necessidades de alunos e sociedade (Drozdová 2008, Ross 2008).

Hynes e Richardson (2007) discutiram a necessidade das universidades se desenvolverem como instituições empresariais. E um dos principais temas na evolução das IESs é o desenvolvimento de novos cursos de ensino superior. Esses cursos devem trazer benefícios para todos: estudantes, mercado de trabalho, empresas, governo, sociedade e para a própria IESs. A academia deve estar alinhada aos interesses de todos os stakeholders envolvidos com a educação superior.

No entanto, o que observa-se é que as IESs utilizam abordagens incompletas para a criação de novos cursos, o que ocasiona deficiências tanto no projeto quanto no lançamento. Isso significa que importantes etapas do processo de desenvolvimento não são executadas corretamente ou, 
simplesmente, não são realizadas. Ideias para novos cursos geradas ao acaso, pesquisas de mercado não realizadas, a não integração de diversas especialidades funcionais e a baixa incidência do uso de testes de mercado para se avaliar a confiabilidade do serviço são algumas prováveis causas para o lançamento de serviços educacionais que não satisfazem seus consumidores, alunos e sociedade, desperdiçando-se recursos escassos (Ross, 2008).

Atualmente, a escolha por um curso superior é mais complexa e, até mesmo, mais importante para os alunos de hoje do que no passado. Os potenciais alunos da atualidade recebem mais informações e têm mais opções. A tomada de decisão por um curso superior envolve diversos fatores, entre eles, a reputação da universidade, o preço da mensalidade, a estrutura física da IES e a empregabilidade do curso escolhido (Mainardes 2007). É preciso compreender quais atributos são chaves para que um indivíduo escolha por um determinado curso de ensino superior (Ariffin et al, 2008).

Segundo os estudos de Brown (2008) e Ross (2008), universidades que possuem maior prestígio apresentam maior facilidade para tornar um sucesso um novo curso superior. Prestígio em educação representa qualidade no ensino, sendo que os potenciais alunos buscam instituições conhecidas para terem melhores oportunidades no mercado de trabalho. Nesse sentido, construir a imagem da IES torna-se um dos requisitos básicos para aumentar a possibilidade de sucesso de um novo curso superior. Como no ensino superior, os candidatos a alunos não podem experimentar o serviço antes de adquiri-lo, a imagem da IES conta muito na hora de se lançar um curso novo para o mercado (Palácio, Meneses e Pérez, 2002).

Outro ponto-chave na oferta de novos cursos de ensino superior é a estrutura física da IES. Ambientes físicos flexíveis, integrados e eficazes, atraem alunos para os cursos, principalmente porque é a estrutura da IES a parte tangível do serviço educacional (Harris e Cullen 2008). Nesse caso, o tamanho da IES pode ser um diferencial. Nesse contexto, universidades grandes possuem mais recursos e podem oferecer mais opções aos indivíduos que buscam educação. Em contrapartida, IESs menores conseguem focar seus esforços em áreas específicas e podem atender melhor ao mercado (Ross, 2008).

Para Vesper e Gartner (1997), desenvolver um novo curso de ensino superior deve seguir um procedimento formal. Inicialmente, é preciso liderança, ou seja, o envolvimento da alta administração da IES na criação de novas soluções para o mercado, uma das principais missões da universidade. Contando com esse apoio, constrói-se uma equipe específica para o desenvolvimento do projeto. Essa equipe vai: coletar e analisar as informações referentes ao novo curso (pesquisas das necessidades do mercado, do potencial de alunos para o novo curso, oportunidades de trabalho para os egressos, entre outros); desenvolver um planejamento de atividades para viabilizar o novo 
curso; avaliar a disponibilidade interna e externa de recursos (humanos, físicos e financeiros); desenvolver os processos administrativos, educacionais e legais referentes ao curso novo; avaliar o desempenho atual da IES e o impacto do novo curso na instituição; analisar a satisfação atual dos estudantes e da sociedade com relação ao que é oferecido pela IES (imagem e reputação). Realizados esses trabalhos, a IES prepara-se para lançar o novo curso no mercado, apoiando-se em marketing intenso e parcerias construídas para tornar o curso um sucesso.

Já Wolff (2008) aposta que um novo curso superior, para se estabelecer nesse competitivo mercado, deve ser: inovador; oferecer valor pedagógico; ser útil aos alunos e à sociedade; contar com o apoio incondicional da gestão da IES; ser viável financeira e tecnicamente; possuir um custo compatível com a futura remuneração dos egressos.

Santos (2003) estabeleceu os atributos a serem levados em conta no desenvolvimento de um novo curso de ensino superior. $\mathrm{O}$ autor elencou quatorze atributos importantes no desenvolvimento de um novo curso: credibilidade da IES (associadas à marca e à tradição); projeção de carreira (reconhecimento acadêmico e nas empresas); formadores de opinião (indicação por profissionais com alta reputação e ex-alunos); corpo docente (associado à experiência acadêmica e profissional dos professores, qualidade da didática e disponibilidade para atender os alunos); infraestrutura (campus, biblioteca, salas, informatização, acesso aos artigos, sites com material didático e ensino a distância); horário (manhã, tarde, noite ou integral); dias da semana (todos os dias da semana, três dias por semana e opções de aulas ao sábados); tempo de conclusão do curso (tempos mínimo e máximo do curso); área de concentração (variedade de ênfases, por exemplo: marketing, finanças, planejamento, organizações, estratégia, logística, recursos humanos, administração pública, empreendedorismo, tecnologia da informação, e-commerce e outras); profundidade das disciplinas (disciplinas com conteúdo mais ou menos aprofundado); preço (associado à custo/benefício, condições de pagamento e bolsas); convênios e parcerias (associados aos convênios com universidades no exterior para realização de pesquisas e intercâmbio, e parcerias com empresas para realização de estágios e estudos de casos); direcionamento/ objetivo do curso (acadêmico, profissional ou composição dos dois níveis); localização (associada à facilidade de acesso e segurança). Partindo desses aspectos, uma equipe multifuncional pode desenvolver e implementar um novo curso superior.

Finalmente, percebe-se poucos e fragmentados estudos sobre o desenvolvimento de novos serviços educacionais, mais especificamente no desenvolvimento de novos cursos de ensino superior. Isso demonstra a necessidade de se desenvolver um modelo que oriente aos gestores das IESs na construção e implementação de novos cursos de nível superior.

Revista Ibero-Americana de Estratégia - RIAE, São Paulo, v. 10, n. 2, p. 58-83, mai./ago. 2011. 
Emerson Wagner Mainardes, Maria José Silva \& Maria José Domingues

\subsection{PROPOSTA DE MODELO PARA O DESENVOLVIMENTO DE NOVOS CURSOS DE ENSINO SUPERIOR}

Tomando por base os estudos de estratégias em serviços, em desenvolvimento de novos serviços, mas, principalmente, em desenvolvimento de novos serviços educacionais, foi possível propor um modelo para a construção de novos cursos em ensino superior.

Como suporte à criação do modelo proposto, analisou-se os resultados das pesquisas realizadas por Vesper e Gartner (1997), Palacio, Meneses e Pérez (2002), Jong e Vermeulen (2003), Santos (2003), Cardoso (2005), Hynes e Richardson (2007), Ariffin et al (2008), Brown (2008), Drozdová (2008), Garcia e Roblin (2008), Harris e Cullen (2008), Ross (2008) e Wolff (2008). Considerando a escassez de estudos na área, foi preciso também observar as atividades que as IESs realizam, ou deveriam realizar, ao decidir oferecer um novo curso de ensino superior. $\mathrm{O}$ modelo pode ser observado na figura 1.

Analisando-se o modelo (figura 1), percebe-se que o processo é dividido em três etapas: antecedentes a criação no novo curso de ensino superior; desenvolvimento do novo curso de ensino superior; e implementação do curso de ensino superior construído.

Figura 1- Proposta de modelo para desenvolvimento de novos cursos superiores.

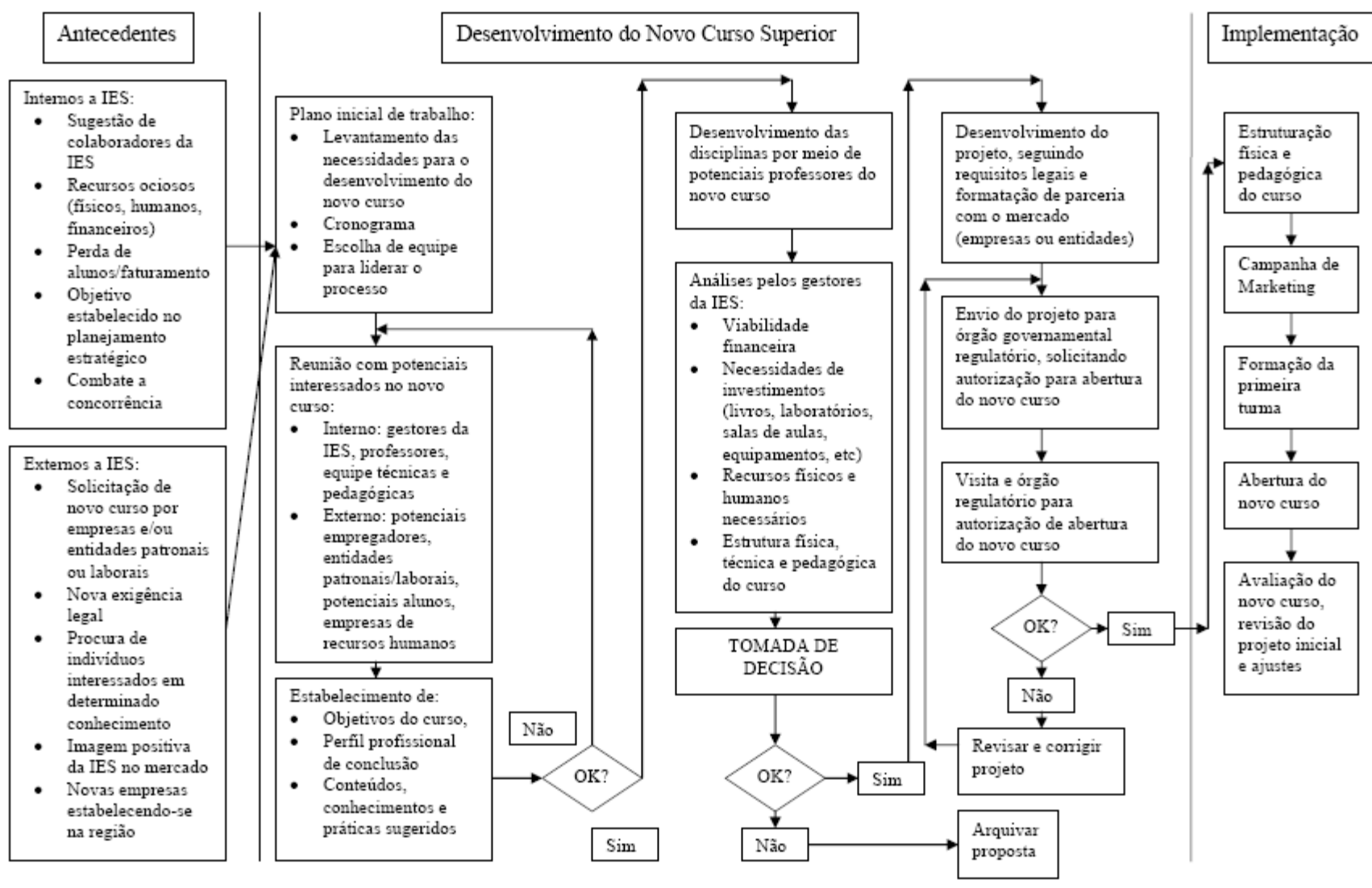

Revista Ibero-Americana de Estratégia - RIAE, São Paulo, v. 10, n. 2, p. 58-83, mai./ago. 2011. 
Proposta de uma Estratégia para o Desenvolvimento de Novos Cursos de Ensino Superior

A etapa de antecedentes refere-se ao surgimento da ideia de desenvolvimento de um novo curso superior. Esses antecedentes podem ter origem interna ou externa da IES. Quando a origem é interna, um novo curso de ensino superior pode ser criado por:

a) Sugestão de pessoas ligadas a própria IES, como professores que dominam determinadas áreas, alunos que têm necessidade de conhecimentos específicos em sua atuação profissional, funcionários que vêem uma boa oportunidade de mercado (Vésper e Gartner, 1997);

b) Recursos parados na IES, ou seja, espaços e salas de aulas subutilizadas, capacidade de equipes de docentes e funcionários técnico-pedagógicos com tempo de sobra para atender mais alunos, disponibilidade de recursos financeiros para novos investimentos (Harris e Cullen, 2008);

c) Perda de alunos e/ou faturamento, levando a alta administração da IES a projetar novos serviços educacionais para recuperar faturamento e volume de alunos (Cardoso, 2005);

d) Cumprir objetivos estabelecidos em planejamento estratégico, como crescimento de oferta de serviços educacionais para o mercado ou mesmo aproveitar oportunidades previamente identificadas (Drozdová, 2008);

e) Combater o crescimento da concorrência de outras IESs, ocupando espaços ainda vagos no mercado (Santos 2003).

Fatores externos à IESs também podem originar novos cursos de ensino superior. Entre esses fatores, pode-se destacar:

a) Empresas e/ou entidades patronais/laborais procuram a IES para solicitar um curso superior que a IES (ou mesmo o mercado) não oferece (Wolff, 2008);

b) Exigências legais podem ocasionar o surgimento de um novo curso superior, como a exigência de formação superior para uma determinada atividade; por exemplo, o governo pode determinar que oficinas mecânicas, obrigatoriamente, devem ter mecânicos com formação superior e como os profissionais dessa área raramente possuem curso nesse nível, ocorrerá uma procura/necessidade de cursos superiores específicos para o setor (Vésper e Gartner, 1997);

c) Também pode acontecer de indivíduos, sem ligação com organizações empresariais ou associativas, venham a procurar a IES e questionar a respeito de um curso que a IES não oferece, e quando esse número de indivíduos se mostrar significativo vale a pena pensar no desenvolvimento do curso em questão (Ross, 2008);

Revista Ibero-Americana de Estratégia - RIAE, São Paulo, v. 10, n. 2, p. 58-83, mai./ago. 2011. 
d) Quando a imagem da IES é forte no mercado, essa pode ser uma boa oportunidade para a oferta de novos cursos superiores (Palácio, Meneses e Pérez, 2002; Ariffin et al, 2008; Brown, 2008);

e) Também quando novas empresas se estabelecem na região onde está situada a IES e começam a procurar profissionais cuja formação não é oferecida localmente, daí surge outra boa oportunidade de criação de cursos superiores que atendam a essa demanda (Santos, 2003).

Passada a etapa dos antecedentes, a segunda parte do modelo é o desenvolvimento de um novo curso de ensino superior. Tendo definido o curso a ser montado (a partir dos antecedentes), primeiramente faz-se um plano inicial de trabalho, onde se estabelecerão a equipe responsável pela construção do novo curso (Vésper e Gartner, 1997), as atividades necessárias para que o novo curso seja desenvolvido (Jong e Vermeulen, 2003) e um cronograma para essas atividades. E o primeiro passo dessa equipe é reunir os potenciais interessados pelo curso a surgir. Esses potenciais interessados podem ser internos (gestores da IES, professores, equipes técnicas e pedagógicas da instituição) ou externos (potenciais empregadores, entidades patronais/laborais, potenciais alunos, empresas de recursos humanos, entre outros), conforme já citaram anteriormente Jong e Vermeulen (2003).

Esse passo é importante por vários motivos: mostra aos públicos interno e externo a pretensão da instituição de ofertar um novo curso superior de interesse desses públicos; faz uma escuta importante das ideias desses públicos a respeito do curso superior a ser desenvolvido. Com a contribuição desses interessados, constrói-se o objetivo geral do curso e o perfil profissional pretendido na conclusão do curso (Santos, 2003). Ambos gerarão os conteúdos, conhecimentos e práticas necessárias para o formado do novo curso.

Com isso em mãos, submete-se a apreciação do público interessado. Se houver alguma divergência, faz-se nova análise dos objetivos, perfil profissional de conclusão e conteúdos, conhecimentos e práticas, fazendo-se nova validação. Com a concordância dos potenciais interessados, parte-se para o desenvolvimento das disciplinas do curso.

Segundo Wolff (2008), esse passo é realizado por especialistas de cada área, mais precisamente acadêmicos, que dominam os conhecimentos específicos das disciplinas previamente definidas. $\mathrm{O}$ procedimento em questão permite também que esses acadêmicos especialistas tornemse possíveis professores do curso em desenvolvimento.

Com o curso estruturado, segue-se a análise da alta gestão da IES (Cardoso, 2005; Hynes e Richardson, 2007). Nesse sentido, deve-se fazer uma análise de viabilidade financeira do novo 
curso, bem como das necessidades de investimentos (legalização do curso, livros, laboratórios, salas de aulas, equipamentos, entre outros) e a disponibilidade interna ou externa de recursos físicos, humanos e financeiros, bem como se há estrutura física, técnica e pedagógica para levar o projeto em frente (Santos, 2003; Harris e Cullen, 2008; Ross, 2008). Essas informações são trazidas pela equipe que lidera o projeto e apresentadas em detalhes para a administração da IES.

Finalizadas as análises, chega o momento chave: abrir o curso ou não? Se a resposta for “não", a recomendação será o arquivamento do processo, para uma nova análise futura. Se a resposta for "sim", parte-se para o desenvolvimento do projeto, respeitando-se os requisitos legais exigidos pelo órgão regulador da educação no país, e para a formalização de parcerias com o mercado (empresas e/ou entidades patronais/laborais).

Segue-se a isso a avaliação desse órgão governamental se o curso deve abrir ou não. Se a resposta for "não", a equipe que lidera o processo na IES pode fazer a revisão do projeto, corrigir as falhas e reenviá-lo para o órgão governamental, solicitando novamente a autorização de funcionamento. Por outro lado, se a avaliação governamental autorizar o início do curso, finaliza-se a etapa de desenvolvimento e parte-se para a implementação do novo curso superior (Santos, 2003).

Essa é a última etapa do modelo. Iniciar um curso superior exige algumas tarefas. A primeira, sem dúvida, é a estruturação física e pedagógica do novo curso superior. É o momento de formar grupos de professores, estabelecer planos de ensino, montar laboratórios e salas de aulas, entre outros (Vésper e Gartner, 1997; Santos, 2003). Em conjunto com esta etapa está a comunicação da novidade para o mercado. Apoiado em marketing intenso, o novo curso superior deve se tornar conhecido para a sociedade (Vésper e Gartner, 1997; Palácio, Meneses e Pérez, 2002). É importante destacar os objetivos do curso, o motivo de sua existência, o perfil profissional de conclusão, as disciplinas que compõem o curso e, principalmente, a possibilidade de empregabilidade do profissional formado. Com uma comunicação adequada, acontece a atração de alunos, formando assim a primeira turma do novo curso superior. Com a turma formada, faz-se abertura do curso. A última etapa é um acompanhamento do desenrolar do novo curso. Problemas surgirão e ajustes no projeto inicial serão necessários. Essa última parte não deve ser esquecida, afinal o serviço educacional, como qualquer outro serviço, é dinâmico e exige acompanhamento constante (Garcia e Roblin, 2008).

Revista Ibero-Americana de Estratégia - RIAE, São Paulo, v. 10, n. 2, p. 58-83, mai./ago. 2011. 
Emerson Wagner Mainardes, Maria José Silva \& Maria José Domingues

\section{COMPARAÇÃO ENTRE O MODELO PROPOSTO E A REALIDADE ATUAL: O CASO DA FACULDADE CENECISTA DE JOINVILLE}

Para comparar o modelo com a realidade vivenciada pelas IESs, descreve-se o caso da Faculdade Cenecista de Joinville. O intuito foi verificar se o processo proposto pelo modelo pode ser viável na realidade de uma IES que procura criar cursos que venham a atender às necessidades do mercado.

\subsection{METODOLOGIA DA PESQUISA}

A descrição do caso segue o modelo de estudo de caso de Yin (2005), consistindo de um estudo exploratório-qualitativo, de corte longitudinal (Triviños, 1987; Marconi e Lakatos, 2002). A escolha da IES investigada deveu-se ao fato de essa instituição afirmar que desenvolve cursos a partir de um processo específico, porém não formalizado na instituição. Entre as IESs consultadas, foi a primeira que admitiu a necessidade de um processo formalizado para o desenvolvimento de novos cursos, bem como considerou utilizar alguns procedimentos para lançar um novo curso superior no mercado.

A coleta de dados utilizou-se de três estratégias: análise de documentos, entrevistas pessoais informais, e observação de campo (Creswell, 1994). Para a análise dos dados, seguiu-se o método de análise de conteúdo para codificar/categorizar os dados coletados, permitindo assim a narrativa histórica do caso, a construção de relações entre as variáveis encontradas e o entendimento do fenômeno estudado (Flick, 2004). A interpretação, em caráter longitudinal, dos dados coletados é descrita na sequência.

\subsection{RESULTADOS DA ANÁLISE DO CASO}

A Faculdade Cenecista de Joinville (FCJ) surgiu em 2000, aproveitando a abertura do mercado educacional brasileiro proporcionada pela Lei de Diretrizes e Bases (LDB) de número 9.394 de 1996 (Planalto, 2007). É uma instituição privada comunitária (filantrópica) e faz parte do Complexo Educacional do Colégio Cenecista José Elias Moreira, instituição de ensino que oferece todos os níveis de ensino (educação infantil, ensino fundamental, ensino médio, educação profissional, licenciatura e pós-graduação). Tem como diretriz o ensino de gestão e empreendedorismo. Oferece quatro cursos de licenciatura (Administração - com ênfases em empresas e negócios, marketing, gestão de pessoas e negócios internacionais, Direito, Turismo e 
Proposta de uma Estratégia para o Desenvolvimento de Novos Cursos de Ensino Superior

Sistemas de Informação) e quatro cursos de tecnologia (Gestão Desportiva e de Lazer, Gestão da Qualidade, Gestão Comercial e Gestão de Logística).

Pode ser considerada uma pequena faculdade, inserida em um ambiente competitivo e hostil. Na mesma cidade, conta com uma IES pública gratuita (UDESC), duas IESs muito tradicionais (UNIVILLE e ACE), duas IESs com grande disponibilidade de recursos (SOCIESC e Grupo Anhanguera - IESVILLE/FATESC), duas IESs ligadas à grandes entidades federais de ensino (SENAI e SENAC), duas pequenas faculdades de perfil semelhante à FCJ (IELUSC e INESA) e uma pequena faculdade agressiva em preços (ASSESSORITEC). Fora isso, em breve, a maior universidade pública do estado (UFSC) abrirá um campus em Joinville/SC, além de cidades próximas também atraírem alunos (UNIVALI em Itajaí, UNERJ, FAMEG e FATEJ em Jaraguá do Sul e FURB e UNIASSELVI em Blumenau).

Ou seja, há um ambiente altamente competitivo, que exige um posicionamento adequado da FCJ para poder sobreviver. Sua opção de posicionamento foi desenvolver e oferecer cursos superiores diferenciados, necessários ao mercado local e não disponíveis nas outras IESs.

Um desses cursos, é o recém-lançado Curso Superior de Tecnologia em Gestão Comercial, objeto desse estudo de caso. As raízes desse curso surgem no aparecimento de um curso de educação profissional, o Curso Técnico em Vendas, desenvolvido em 2001 e lançado em 2002, que tem como objetivo formar profissionais de vendas para o mercado. O curso técnico foi um sucesso imediato, com alta empregabilidade dos formados, despertando o interesse dos donos de lojas na cidade. Com a melhoria da competência dos vendedores do mercado, ocasionada pelo inédito curso técnico, a Câmara dos Dirigentes Lojistas de Joinville (CDL Joinville), associação empresarial que reúne os proprietários de lojas da cidade, procurou a FCJ em 2005 para propor o desenvolvimento de um curso superior que preparasse os gerentes das lojas (chefes dos vendedores), sendo este o antecedente que originou o novo curso (primeiro item dos fatores externos que geram a construção de um novo curso de ensino superior).

Com a ideia aceita, montou-se uma equipe com o gerente técnico-pedagógico da IES, o gestor do curso superior de Administração e um professor da área de vendas para construir o projeto do curso. O primeiro passo foi reunir os principais interessados no novo curso. Reuniu-se então professores, consultores, empregadores, gerentes de lojas, empresas de recursos humanos, pedagogos, para que se estabelecesse os objetivos do curso, o perfil profissional de conclusão e os conhecimentos a desenvolver nos futuros alunos. Depois de três reuniões, concluiu-se a discussão dos temas e sugeriu-se as disciplinas do curso.

O passo seguinte foi contatar professores para o desenvolvimento de cada disciplina. Mais duas reuniões foram necessárias para orientar e esclarecer os professores, todos ligados à IES. No

Revista Ibero-Americana de Estratégia - RIAE, São Paulo, v. 10, n. 2, p. 58-83, mai./ago. 2011. 
início de 2006, concluiu-se o desenvolvimento das disciplinas do curso. Com o projeto pronto, ele foi apresentado à direção da IES. Como o curso exigia baixos investimentos, e contava com um forte parceiro (CDL Joinville) e com os recursos internos disponíveis (professores, estrutura técnica-pedagógica, estrutura física), decidiu-se levar em frente o desenvolvimento do novo curso.

O próximo passo era montar o projeto do curso para submissão e posterior aprovação do Ministério da Educação e Cultura do Brasil (MEC). A montagem do projeto levou três meses. Quando finalizado, foi enviado para o MEC no final do primeiro semestre de 2006. Somente em meados de 2007, o MEC se pronunciou e agendou a visita de autorização do curso na IES. A visita foi realizada em setembro de 2007 e o curso foi autorizado para ser iniciado.

Chegou então o momento da implementação do curso, última etapa do modelo. Como os recursos estavam todos disponíveis, iniciou-se a campanha de captação de alunos para o curso. Com o apoio da CDL Joinville, montou-se, a duras penas, a primeira turma, com o número mínimo de alunos exigido pela gestão da IES (35 alunos). O curso começou no início de 2008 e está sendo avaliado para ajustes posteriores. O nível de satisfação dos alunos pode ser considerado médio.

Analisando-se o caso descrito, percebe-se que ele segue uma sequência próxima ao modelo apresentado na figura 1. Entre os problemas que surgiram e que levaram a um aprendizado da organização estão:

- O procedimento de construção do curso não foi formalizado e muitas das etapas foram realizadas por ideia dos integrantes da equipe ou por uma necessidade exigida no momento;

- A pesquisa de mercado não foi bem aprofundada, pois, posteriormente, percebeu-se que os potenciais alunos do curso não recebiam rendimentos suficientes para pagar a mensalidade, algo encontrado anteriormente por Wolff (2008), sendo que não é corriqueiro os proprietários de lojas ajudarem os seus funcionários nos estudos deles;

- A CDL Joinville, apesar de ser uma entidade forte e representativa, teve dificuldades em captar alunos;

- Os empregadores não exigem formação superior para gerentes de lojas, o que possibilita pagar salários menores;

- A campanha de marketing da IES foi pouco eficaz, algo comum entre as IESs, pois o marketing educacional ainda é recente no Brasil. 
Proposta de uma Estratégia para o Desenvolvimento de Novos Cursos de Ensino Superior

Enfim, o curso é uma inovação para o mercado local, atende uma necessidade histórica (formação para o comércio), porém ainda sofre resistência por ser uma novidade. Percebeu-se que será preciso um trabalho árduo para perpetuar o curso em questão.

\section{CONSIDERAÇÕES FINAIS}

Atualmente, as instituições educacionais, principalmente as de ensino superior, estão inseridas em um mercado altamente competitivo (Hynes e Richardson, 2007; Drozdová, 2008; Ross, 2008). Emerge assim a necessidade de que cada IES transforme sua gestão, mudando o seu modelo atual para um mais empresarial, provendo novos serviços educacionais que atendam os alunos e a sociedade de maneira mais eficaz, perpetuando assim a instituição. Dessa forma, exige-se a construção de um modelo específico para o desenvolvimento de novos serviços no setor educacional (Edgett, 1993), principalmente na oferta de novos cursos de ensino superior.

Desenvolver novos cursos de ensino superior depende de um planejamento adequado (Santos, 2003; Syson e Perks, 2004; Ottenbacher, Gnoth e Jones, 2006), integrando fatores internos às IESs (suas competências organizacionais) e os fatores externos à instituição (seu meio envolvente). A adequação da IES para o desenvolvimento de novos serviços educacionais tem sido a chave para novos cursos de ensino superior de sucesso no mercado (Jong e Vermeulen, 2003).

No entanto, Mendes e Toledo (1997) já afirmaram: as IESs baseiam-se em abordagens incompletas para a criação de novos cursos de ensino superior, que resultam em deficiências no projeto e na implementação do novo curso. Dessa forma, o objetivo no qual se baseou a investigação realizada foi propor um modelo que auxilie aos gestores das IESs na concepção, desenvolvimento e implementação de um novo curso de ensino superior, que pode ser muito útil para as organizações do setor.

Buscava-se desenhar um modelo que instruísse os gestores das IESs na construção de um novo curso de ensino superior. Com a análise das poucas pesquisas a respeito do assunto, propôs-se um modelo que esclarece o desenvolvimento de um novo curso de ensino superior. Complementarmente, identificou-se os antecedentes (internos e externos) que levam a geração do novo curso de ensino superior, determinou-se os passos para o desenvolvimento do curso a surgir e definiu-se as etapas na implementação do referido curso. Pode-se dizer que o modelo formal apresentado aumenta os cuidados que os gestores das IESs devem ter para lançar um novo curso de ensino superior no mercado (como pode ser observado no caso apresentado), aumentando, por consequência, as chances de sucesso do tal curso.

Revista Ibero-Americana de Estratégia - RIAE, São Paulo, v. 10, n. 2, p. 58-83, mai./ago. 2011. 
Como limitações encontradas no estudo realizado, pode-se citar duas: (a) a raridade de estudos que tratam da oferta de novos serviços educacionais, especialmente novos cursos de ensino superior; (b) um estudo de caso não permite a generalização dos resultados obtidos. Com relação a quase inexistência de estudos sobre o tema tratado aqui, esse fator limitou, de forma significativa, as comparações entre o caso analisado e outros casos semelhantes, tornando o processo de construção do conhecimento e entendimento do fenômeno algo bastante indutivo, exigindo dos autores do estudo uma capacidade maior de abstração nas análises efetuadas. Quanto à falta de confirmação estatística do modelo, por ser um estudo de caráter exploratório-qualitativo com a análise comparativa de um único caso, é provável que, em estudos futuros, o modelo proposto seja alterado, conformando-se com a realidade do fenômeno em questão. Portanto, não é possível generalizar o modelo proposto, sendo assim necessárias mais pesquisas que coloquem à prova o modelo apresentado nesse estudo.

Por fim, buscou-se contribuir para um assunto pouco investigado na academia: o desenvolvimento de novos serviços educacionais. Considerando-se a pouca incidência de pesquisas na área da estratégia em novos serviços educacionais, pretendeu-se aqui abrir uma discussão a respeito da sobrevivência das instituições que oferecem ensino superior, ao produzir para o mercado cursos de ensino superior que convirjam para as necessidades da sociedade desse século XXI. Em termos práticos, o modelo apresentado pode ser útil aos gestores das IESs da atualidade. Em termos acadêmicos, apresenta-se um fenômeno pouco estudado e que requer mais pesquisas para ser compreendido.

\section{REFERÊNCIAS}

Aranda, D. (2003). Service operations strategy, flexibility and performance in engineering consulting firms. International Journal of Operations \& Production Management, 23(11), 14011421. http://dx.doi.org/10.1108/01443570310501907

Ariffin, A., Ahmad, A., Ahmad, M. \& Ibrahim, M. (2008). Determining decision-making styles and demographic differences in selecting higher education services among Malaysian. International Journal of Business and Society, 9(1), 12-36.

Armistead, C. (1990). Service operations strategy: Framework for matching the service operations task and the service delivery system. International Journal of Service Industry Management, $1(2), 6-16$. http://dx.doi.org/10.1108/EUM0000000002800 
Bateson, J. \& Hoffman, K. (2001). Marketing de serviços. Porto Alegre: Bookman.

Blois, K. (1983). The structure of service firms and their marketing policies. Strategic Management Journal, 4(1), 251-261. http://dx.doi.org/10.1002/smj.4250040306

Blok, C., Luijkx, K., Meijboom, B. \& Schols, J. (2010). Modular care and service packages for independently living elderly. International Journal of Operations \& Production Management, 30(1), 75-97.

http://dx.doi.org/10.1108/01443571011012389

Brown, R. (2008). Higher education and the market. Perspectives: Policy and Pratice in Higher Education, 12(3), 78-83. http://dx.doi.org/10.1080/13603100802181125

Bucki, J. \& Pesqueux, Y. (2000). Flexible workshop: About the concept of flexibility. International Journal of Agile Management Systems, 2(1), 62-70.

http://dx.doi.org/10.1108/14654650010312615

Cardoso, E. (2005). Ambientes de ensino distribuído na concepção e desenvolvimento da universidade flexível. Tese de Doutoramento em Sistemas de Distribuição: Área do Ensino Distribuído, Escola de Engenharia, Universidade do Minho, Minho.

Carman, J. \& Langeard, E. (1980). Growth strategies for service firms. Strategic Management Journal, 1(1), 7-22.

http://dx.doi.org/10.1002/smj.4250010103

Creswell, J. (1994). Research design: Qualitative \& quantitative approaches. Thousand Oaks, California: Sage Publications Inc.

Droege, H., Hildebrand, D. \& Forcada, M. (2009). Innovation in services: Present findings, and future pathways. Journal of Service Management, 20(2), 131-155.

http://dx.doi.org/10.1108/09564230910952744

Drozdová, M. (2008). New business model of educational institutions. E+M Ekonomie $a$ Management, 1, 60-68.

Edgett, S. (1993). Developing new financial services within U.K. building societies. International Journal of Bank Marketing. 11(3), 35-43.

http://dx.doi.org/10.1108/02652329310027701

Edvardsson, B., Haglund, L. \& Mattsson, J. (1995). Analysis, planning, improvisation and control in the development of new services. International Journal of Service Industry Management, 6(2), 24-35.

http://dx.doi.org/10.1108/09564239510084923

Revista Ibero-Americana de Estratégia - RIAE, São Paulo, v. 10, n. 2, p. 58-83, mai./ago. 2011. 
Emerson Wagner Mainardes, Maria José Silva \& Maria José Domingues

Findlow, S. (2008). Accountability and innovation in higher education: A disabling tension? Studies in Higher Education, 33(3), 313-329.

http://dx.doi.org/10.1080/03075070802049285

Fitzsimmons, J. \& Fitzsimmons, M. (2000). Administração de serviços: Operações, estratégia e tecnologia de informação (2. ed.). Porto Alegre: Bookman.

Flick, U. (2004). Uma introdução à pesquisa qualitativa (2 ed.). Porto Alegre: Bookman.

Froehle, C. \& Roth, A. (2007). A resource-process framework of new service development. Production and Operations Management, 16(2), 169-188. http://dx.doi.org/10.1111/j.1937-5956.2007.tb00174.x

Garcia, L. \& Roblin, N. (2008). Innovation, research and professional development in higher education: Learning from our own experience. Teaching and Teacher Education, 24, 104-116. http://dx.doi.org/10.1016/j.tate.2007.03.007

Harris, M. \& Cullen, R. (2008). Renovation as innovation: Transforming a campus symbol and a campus culture. Perspectives: Policy and Pratice in Higher Education, 12(2), 47-51. http://dx.doi.org/10.1080/13603100801957418

Hurmelinna-Laukkanen, P. \& Ritala, P. (2010). Protection for profiting from collaborative service innovation. Journal of Service Management, 21(1), 6-24.

http://dx.doi.org/10.1108/09564231011025092

Hynes, B. \& Richardson, I. (2007). Entrepreneurship education: A mechanism for engaging and exchanging with the small business sector. Education + Training, 49(8/9), 732-744.

Jonhston, R. (1999). Service operations management: Return to roots. International Journal of Operations \& Production Management, 19(2), 104-124.

http://dx.doi.org/10.1108/01443579910247383

Jong, J. de \& Vermeulen, P. (2003). Organizing successful new service development: A literature review. Management Decision, 41(9), 844-858.

http://dx.doi.org/10.1108/00251740310491706

Kindström, D. \& Kowalkowski, C. (2009). Development of industrial service offerings: a process framework. Journal of Service Management, 20(2), 156-172.

http://dx.doi.org/10.1108/09564230910952753

Lovelock, C. (1996). Service marketing. New York: Prentice-Hall.

Revista Ibero-Americana de Estratégia - RIAE, São Paulo, v. 10, n. 2, p. 58-83, mai./ago. 2011. 
Macintosh, G. (2009). The role of rapport in professional services: Antecedents and outcomes. Journal of Services Marketing, 23(2), 70-78.

http://dx.doi.org/10.1108/08876040910946332

Mainardes, E. W. (2007). Atração e retenção de alunos em cursos de graduação em administração das instituições particulares de ensino superior de Joinville, SC. Dissertação de Mestrado, Programa de Pós-Graduação em Administração, Centro de Ciências Sociais Aplicadas, Universidade Regional de Blumenau, Blumenau.

Marconi, M. \& Lakatos, E. (2002). Técnicas de pesquisa: Planejamento e execução de pesquisas, amostragens e técnicas de pesquisas, elaboração, análise e interpretação de dados. São Paulo: Atlas.

Mathyssens, P. \& Vandenbempt, K. (1998). Creating competitive advantage in industrial services. Journal of Business \& Industrial Marketing, 13(4/5), 339-355. http://dx.doi.org/10.1108/08858629810226654

Mendes, G. \& Toledo, J. (1997). Qualidade em serviços: O papel da função de desenvolvimento de novos serviços. Artigo apresentado no XVII Encontro Nacional de Engenharia de Produção (ENEGEP), Gramado/RS.

Meyer Jr., V. e Murphy, J. (2003). Dinossauros, gazelas \& tigres: novas abordagens da administração universitária, um diálogo Brasil EUA (2 ed. Ampliada). Florianópolis: Insular.

Michael, S. (2004). In search of universal principles of higher education management and applicability to Moldavian higher education system. The International Journal of Educational Management, 18(2), 118-137.

http://dx.doi.org/10.1108/09513540410522252

Miles, I. (2001). Services innovation: A reconfiguration of innovation studies. Discussion Paper Series. Manchester: The University of Manchester.

Mok, K. (2003) Decentralization and marketization of education in Singapore: A case study of the school excellence model. Journal of Educational Administration, 41(4), 348-366.

$\underline{\text { http://dx.doi.org/10.1108/09578230310481621 }}$

Nayyar, P. (1990). Information asymmetries: A source of competitive advantage for diversified service firms. Strategic Management Journal, 11(1), 513-519.

$\underline{\text { http://dx.doi.org/10.1002/smj.4250110703 }}$

Ottenbacher, M., Gnoth, J. \& Jones, P. (2006). Identifying determinants of success in development of new high-contact services: Insights from the hospitality industry. International Journal of Service Industry Management, 17(4), 344-363.

http://dx.doi.org/10.1108/09564230610680659

Revista Ibero-Americana de Estratégia - RIAE, São Paulo, v. 10, n. 2, p. 58-83, mai./ago. 2011. 
Palacio, A., Meneses, G. \& Pérez, P. (2002) The configuration of the university image and its relationship with the satisfaction of students. Journal of Educational Administration, 40(5), 486505. http://dx.doi.org/10.1108/09578230210440311

Planalto, Palácio do. (2007). Lei número 9.394, de 20 de dezembro de 1996. Presidência da República, Casa Civil, Subchefia para Assuntos Jurídicos. Recuperado em 13 de Setembro 2011 <http://www. planalto.gov.br/CCNILI_03/leias/L9394.htm>.

Porter, M. (1980). Competitive strategy: techniques for analyzing industries and competitors. New York: Free Press.

Porter, M. (1985). Competitive advantage: creating and sustaining competitive performance. New York: Free Press.

Rebelo, L. \& Erdmann, R. (2003). Considerações sobre o estudo de estratégias competitivas no setor de serviços sob o enfoque das escolas de planejamento e de aprendizado. Revista Alcance, 10(2), 191-228.

Ross, S. (2008). Searching for strategic opportunities. Academy of Strategic Management Journal, 7, 35-46.

Santos, L. (2003). Desenvolvimento de serviços na área de educação: Uma aplicação de análise conjunta nos cursos de mestrado em administração de empresas. Dissertação de Mestrado, Programa de Pós-Graduação em Administração de Empresas, Departamento de Administração, Pontifícia Universidade Católica do Rio de Janeiro, Rio de Janeiro.

Segal-Horn, S. (2006). Strategy in service organizations. In D. Faukner \& A. Campbell (Eds.), Strategy: a strategy overview and competitive strategy (472-506). Oxford: University Press.

Skaggs, B. \& Youndt, M. (2004). Strategic positioning, human capital and performance in service organizations: A customer interaction approach. Strategic Management Journal, 25(1), 85-99.

http://dx.doi.org/10.1002/smj.365

Storey, C. \& Kelly, D. (2001). Measuring the performance of new service development activities. The Service Industries Journal, 21(2), 71-90.

http://dx.doi.org/10.1080/714005018

Syson, F. \& Perks, H. (2004). New service development: A network perspective. Journal of Services Marketing, 18(4), 255-266.

http://dx.doi.org/10.1108/08876040410542254

Tam, F. (2007). Rethinking school and community relations in Hong Kong. International Journal of Educational Management, 21(4), 350-366.

http://dx.doi.org/10.1108/09513540710749555

Revista Ibero-Americana de Estratégia - RIAE, São Paulo, v. 10, n. 2, p. 58-83, mai./ago. 2011. 
Tannery, F. (2001). Le management stratégique des services: Synthèse bibliographique et repérage des questions génériques. Finance Contrôle Stratégie, 4(2), 215-259.

Triviños, A. (1987). Introdução a pesquisa em ciências sociais: a pesquisa qualitativa em educação. São Paulo: Atlas.

Urban, G. \& Hauser, J. (1993). Design and marketing of new products (2 ed.). New Jersey: Prentice Hall.

Vesper, K. \& Gartner, W. (1997). Measuring progress in entrepreneurship education. Journal of Business Venturing, 12, 403-421.

http://dx.doi.org/10.1016/S0883-9026(97)00009-8

Voss, C. \& Hsuan, J. (2009). Service architecture and modularity. Decision Sciences, 40(1), 541569.

http://dx.doi.org/10.1111/j.1540-5915.2009.00241.x

Wolff, W. (2008). "A chimera of sorts": Rethinking educational technology grant programs, courseware innovation, and the language of educational change. Computers \& Education, 51, 1184-1197.

http://dx.doi.org/10.1016/j.compedu.2007.11.005

Yin, R. (2005). Estudo de caso: planejamento e métodos (3 ed.). Porto Alegre: Bookman.

\section{Recebido: 15/03/2011}

Aprovado: 02/06/2011

Revista Ibero-Americana de Estratégia - RIAE, São Paulo, v. 10, n. 2, p. 58-83, mai./ago. 2011. 